\title{
Preliminary Economic Evaluation of the Alkox Process
}

\author{
L. J. Silva \\ M. A. Lilga \\ D. M. Camaioni \\ L. J. Snowden
}

September 1991

Prepared for the U.S. Department of Energy under Contract DE-AC06-76RLO 1830

Pacific Northwest Laboratory

Operated for the U.S. Department of Energy

by Battelle Memorial Institute 


\title{
DISCLAIMER
}

This report was prepared as an account of work sponsored by an agency of the United States Government. Neither the United States Government nor any agency thereof, nor Battelle Memorial Institute, nor any of their employees, makes any warranty, expressed or implied, or assumes any legal liability or responsibility for the accuracy, completeness, or usefulness of any information, apparatus, product, or process disclosed, or represents that its use would not infringe privately owned rights. Reference herein to any specific commercial product, process, or service by trade name, trademark, manufacturer, or otherwise does not necessarily constitute or imply its endorsement, recommendation, or favoring by the United States Government or any agency thereof, or Battelle Memorial Institute. The views and opinions of authors expressed hercin do not necessarily state or reflect those of the United States Government or any agency thereof.

\author{
PACIFIC NORTHWEST LABORATORY \\ operated by \\ BATTELLE MEMORIAL INSTITUTE \\ for the \\ UNITED STATES DEPARTMENT OF ENERGY \\ under Contract DE-ACO6-76RLO 1830
}

Printed in the United States of America

Available to DOE and DOE contractors from the

Office of Scientific and Technical Information, P.O. Box 62, Oak Ridge, IN 37831; prices available from (615) 576-8401. FTS 626-8401.

Available to the public from the National Technical Information Service, U.S. Department of Commerce, 5285 Port Royal Rd., Springfield, VA 22161. 
PNL --7807

DE92 000163

PRELIMINARY ECONOMIC EVALUATION OF THE ALKOX PROCESS

L. J. Silva

M. A. Lilga

D. M. Camaioni

L. J. Snowden

September 1991

Prepared for the U.S. Department of Energy under Contract DE-AC06-76RLO 1830

Pacific Northwest Laboratory

Richland, Washington 99352 


\section{SUMMARY}

A new chemical process has been invented at Battelle Pacific Northwest Laboratories for converting alkanes to alcohols. This new chemistry has been named the "Alkox Process." Pacific Northwest Laboratory ${ }^{(a)}$ prepared a preliminary economic analysis for converting cyclohexane to cyclohexanol, which may be one of the most attractive applications of the Alkox process. A process flow scheme and a material balance were prepared to support rough equipment sizing and costing. The results from the economic analysis are presented in the non-proprietary section of this report. The process details, including the flow diagram and material balance, are contained in separate section of this report that is proprietary to Battelle.

A plant designed to produce 200 million pounds per year of cyclohexanol via the Alkox process would have a payback period of about four years and a before-tax discounted cash flow rate-of-return of $22 \%$, assuming a 20 -yr plant life. This preliminary economic analysis is based on limited laboratory information about the process. Since the Alkox process is at an early stage of development, several important process parameters are not yet well defined. Selection of the key process parameters for this study is described in the proprietary section.

Process economics may be improved by reducing constraints of process parameters. For example, improving the product yield or optimizing ratios of reactants may further reduce equipment sizes and operating costs. Economic attractiveness would also improve with more efficient heat recovery.

There are also process uncertainties that could significantly reduce the economic attractiveness of this process. For example, the main reactor has not been developed, designed, or demonstrated. Also, this study is based on ideal vapor-liquid equilibrium behavior for distillation in the absence of

(a) Operated for the U.S. Department of Energy by Battelle Memorial Institute under Contract DE-AC06-76RLO 1830. 
other information. However, the presence of azeotropes or other non-ideal behavior is strongly suspected, which would make process distillations more difficult and expensive than estimated for this analysis. 


\section{CONTENTS}

NON-PROPRIETARY SECTION

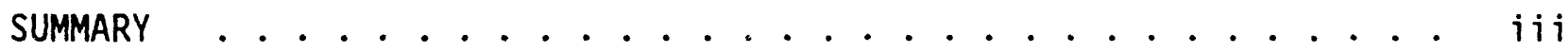

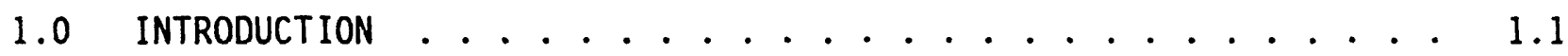

1.1 DIRECT OXIDATION . . . . . . . . . . . . . . . . 1.1

1.2 CYCLOHEXANE OXIDATION . . . . . . . . . . . . . . 1.2

2.0 CONCLUSIONS AND RECOMMENDATIONS . . . . . . . . . . . . 2.1

3.0 ECONOMIC ANALYSIS . . . . . . . . . . . . . . . . 3.1

3.1 PLANT CAPACITY . . . . . . . . . . . . . . . 3.1

3.2 INVESTMENT COST . . . . . . . . . . . . . . . . 3.1

3.3 MANUFACTURING COSTS . . . . . . . . . . . . . 3.2

3.4 MARKET ANALYSIS .................. 3.4

4.0 REFERENCES ....................... 4.1

PROPRIETARY SECTION

APPENDIX A: PROCESS CHEMISTRY ..................... A.I

APPENDIX B: PROCESS FLOW DESCRIPTION . . . . . . . . . . . . . B.1

APPENDIX C: KEY PROCESS PARAMETERS .................. c. . . . 


\section{IABLES}

3.1 Capital Investment Estimate . . . . . . . . . 3.2

3.2 Manufacturing costs ................... 3.3

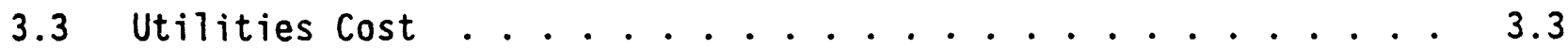

3.4 Overall Cyclohexane Oxidation Economics via Alkox . . . . 3.4 


\subsection{INTRODUCTION}

A new chemical process for converting alkanes to alcohols has been invented at Battelle, Pacific Northwest Laboratories. Initial laboratory results indicate a potential for significant industrial impact on alkane oxidation by improving process yields and subsequent reductions in energy consumption. This new alkane oxidation process has been named the "Alkox Process."

The purpose of this report is to present a preliminary economic analysis of the process. This economic analysis conducted by Pacific Northwest Laboratory is based on a rough material balance and approximate sizing of major equipment to determine required investment and operating costs for an industrial-scale unit.

Potential commercial uses for the Alkox Process include production of oxygenates for fuels and production of chemical feedstocks for other processes. For example, the Clean Air Act of 1990 mandates future use of oxygenates in gasoline. The Alkox Process could be used to produce butanol for fuel blending or isobutanol for manufacture of methyl-tertiary butyl ether (MTBE), which is becoming an important octane booster in gasoline.

The results of this study are organized into a two-section report. The first section, which is non-proprietary, contains the results of this economic analysis. The second section, which is proprietary to Battelle, contains detailed technical information relating to the Alkox technology and the basis for the results presented in this report.

\subsection{DIRECT OXIDATION}

Laboratory-scale demonstrations of a new route to convert alkanes to alcohols have been conducted for converting methane to methanol, butane to butanol, and cyclohexane to cyclohexanol. Initial laboratory results indicate that this process is much more efficient than conventional alkane oxidation. In addition, the reaction occurs at room temperature and atmospheric pressure. The chemistry of this reaction is described in proprietary documents and in the proprietary section of this report. 
In the past, direct oxidation of an alkane to the corresponding alcohol has been very difficult because the alcohol is usually more reactive than the alkane in an oxidizing environment. The alcohol that is produced quickly reacts further to unwanted byproducts. Therefore, traditional oxidation steps are expensive and energy intensive due to oxidation processes that are inefficient and are operated at low conversion. For methanol, the traditional route is to convert methane to synthesis gas via partial combustion. The synthesis gas is converted into methanol in a separate step. These reactions require high temperature and high pressure.

Conventional direct oxidation of cyclohexane to cyclohexanol is conducted at temperatures above $140^{\circ} \mathrm{C}$ and $100 \mathrm{psig}$ in the presence of an aldehyde or ketone initiator and a soluble metal catalyst (Mcketta and Cunningham 1977). The reaction conversion is very low--typically in the range of 6 to 9\%--in order to maximize the overall yield of desired ketone-alcohol (KA) product mixture.

\subsection{CYCLOHEXANE OXIDATION}

The economic evaluation presented here focuses on the case of converting cyclohexane to cyclohexanol. Cyclohexanol is used primarily as a chemical feedstock for the production of adipic acid. Adipic acid is combined with hexamethylene diamine to produce the monomer base for nylon fiber and plastics. More than $90 \%$ of the adipic acid produced is used to manufacture nylon (McKetta and Cunningham 1977). Cyclohexane is also used for producing caprolactam, which is used to produce nylon 6 . About $90 \%$ of the cyclohexane produced is used to make either nylon 66 or nylon 6 (Chemical \& Engineering News 1986).

The oxidation of cyclohexane to cyclohexanol was chosen for consideration because

- The cyclohexanol product is used to produce a high value-added product, not just a fuel blending component.

- Preliminary laboratory experiments indicate that Alkox process yields are greater for cyclohexanol than for yields of methanol or butanol. In addition, oxidation to butanol has the disadvantage that the process is not specific for production of butanol isomers. 


\subsection{CONCLUSIONS AND RECOMMENDATIONS}

A plant designed to produce 200 million pounds per year of cyclohexanol via the Alkox Process would have a payback period of about four years and a before-tax discounted cash flow rate-of-return of $22 \%$ assuming a 20 -yr plant life. This preliminary economic analysis is based on limited laboratory information about the process. Since the Alkox process is at an early stage of development, several important process parameters are not yet well defined. Selection of the key process parameters for this study is discussed in the proprietary section of this report.

Areas where further development may improve the economics include

- improving the ratios of reactants to cyclohexane. The laboratory reactions are carried out in very dilute solution. This analys is is based on a more optimistic scenario. However, determining the limits of concentrations for reactants may further reduce equipment sizes and operating costs.

- improving heat recovery of the process by optimizing process conditions. Steam heating costs make up about $70 \%$ of the total manufacturing cost. Reducing heat requirements by $20 \%$ with improved heat recovery may boost the rate-of-return to about $40 \%$.

- defining and improving of the main reactor design. The cost of the main reactor is the most significant item in the capital cost estimate.

- improving the yield of cyclohexanol in the main reaction.

- reducing constraints of other key process parameters and considering alternative process steps, which are both discussed in the proprietary section.

The economics of this process may be different if adipic acid production rather than cyclohexanol production is evaluated. It is possible that combining the Alkox Process with the nitric acid oxidation process for producing adipic acid would result in increased overall efficiency.

There are also technical uncertainties, which could significantly reduce the economic attractiveness of this process. For example, 
- the concept for the design of the main reactor has not been demonstrated. Simple scale-up of the laboratory reactor system would be expensive. This study is based on a different reactor concept, which has not been developed, designed, or demonstrated.

- the economic analysis is based on ideal vapor-liquid equilibrium behavior in the absence of other information. The thermodynamic properties of the components used in the reaction are not well known. However, the presence of azeotropes or other non-ideal behavior is strongly suspected, which could make process separations more difficult and expensive than estimated for this analysis.

Further development work should include verifying and optimizing required process parameters to support a more accurate estimate of the economic attractiveness of this process. The design of the main reactor should be defined, and the technical feasibility of the reactor design should be demonstrated. Vapor-liquid equilibrium and liquid-liquid solubility data for the system components should be collected for determining optimum process separation steps. In addition, alternative process flow schemes should be considered for improving the economics. 


\subsection{ECONOMIC ANALYSIS}

This section summarizes the preliminary economic analysis of a process to convert cyclohexane to cyclohexanol using the Alkox chemistry. The capital investment and operating costs of an industrial-scale plant were estimated using approximate plant costing techniques.

\subsection{PLANT CAPACITY}

This economic analysis is based on a plant production capacity of 200 million pounds of cyclohexanol per year. This capacity was chosen for comparison with conventional cyclohexane oxidation processes. Generally, adipic acid production via conventional cyclohexane oxidation is attractive for large-scale manufacture of greater than 100 million pounds per year (Mcketta and Cunningham 1977).

Results from the material balance and equipment-sizing calculations conducted for this study indicate that 200 millions pounds per year may be approaching the largest scale practical for a single-train plant. At this plant capacity, the equipment required for some of the separation steps approach the maximum practical size without having to separate the flow into two parallel processing steps. Therefore, this economic analysis should take fult advantage of economies of scale.

The operating factor selected for this study is 0.9 . This operating factor was selected to provide for reasonable down-time for both scheduled maintenance and unscheduled shut-downs.

\subsection{INVESTMENT COST}

Table 3.1 shows the estimated capital investment cost. The on-plot capital investment was estimated by determining sizes for individual items of major process equipment, such as vessels, distillation columns, heat exchangers, and pumps. An equipment 1 ist including sizes of major equipment is included in the proprietary section. The equipment costs were multiplied 
TABLE 3.1. Capital Investment Estimate ${ }^{(a)}$

Plant Capacity, million pounds/year 200 Operating Factor 0.9

\section{SMillion}

On-plot equipment

87

off-plot facilities

22

TOTAL

Approximately 110

(a) The investment cost is based on average 1991 U.S. dollars.

by installation factors and inflation factors to determine the 1991 capital investment cost of the on-plot facilities (Guthrie 1969; Hall et al. 1982; Perry 1984; Farrar 1991).

Off-plot facilities were estimated to cost about $25 \%$ of the on-plot facilities. The off-plot facilities include such items as the control room, storage tanks, other buildings and support facilities. For example, the plant requires utilities such as steam and electricity, which would be supplied by installing new facilities or adding capacity to existing facilities. off-plot costs are highly variable and site-specific. The $25 \%$ factor is probably adequate for the case where the plant is built in an existing petrochemical complex, but may be too low if the plant were a stand-alone facility.

\subsection{MANUFACTURING COSTS}

Table 3.2 shows the manufacturing costs for the Alkox cyclohexanol plant. The feed and product values are the same as reported in a recent issue of the Chemical Marketing Reporter.

The bases for utility costs are shown in Table 3.3. Utility costs are site-specific. Cost variations are due to differences in how the particular utility is supplied. For example, a refinery cogeneration plant may be able to supply electricity at less cost than buying electricity from the grid of the local power company. Steam costs depend on the cost of fuel used in steam 
TABLE 3.2. Manufacturing Costs

\section{$\$ / 1 \mathrm{~b}$ Cyclohexanol \$Million/Year}

$\begin{array}{lcr}\text { Cyclohexane Feedstock Cost } & 0.15 & 30.25 \\ \text { (@ 1.16/galion) } & & \\ \text { Utilities } & 0.0098 & 1.95 \\ \text { Electricity } & 0.505 & 100.93 \\ \text { Steam } & <0.0001 & 0.02 \\ \text { Cool ing Water } & 0.0036 & 0.72 \\ \text { Operating Labor } & 0.0006 & 0.11 \\ \text { Supervisory Labor } & 0.0165 & 3.3 \\ \text { Maintenance } & 0.0165 & 3.3 \\ \text { Taxes and Insurance } & 0.0155 & 3.1 \\ \text { Overhead Expenses } & & 144 \\ \text { TOTAL } & 0.72 & \end{array}$

TABLE 3.3. Utilities cost

$\begin{array}{lr}\text { Electricity, cents per } \mathrm{kW} \text {-hour } & 6 \\ \text { Steam, \$ per 1000 pounds } & 12 \\ \text { Cooling Water, cents per } 1000 \text { gallons } & 10\end{array}$

generation, as well as the capital cost of new or incremental facilities required. For this study, we attempted to select likely "average" values for utility costs.

We have not included any costs for chemicals, solvents, or catalyst. The process will use air for oxidation and will not require purchased oxygen. The other components in the system will be completely recovered and recycled.

The operating labor cost is based on employing three operators per shift. Two operators would be stationed in the control room and one operator would be assigned in the $\mathrm{plant}$. This is a typical arrangement for a fairly large, complex plant.

The remaining manufacturing costs were estimated using ratios typical for chemical processing facilities. Supervisory labor costs were estimated to be about $15 \%$ of the operating labor cost. Maintenance costs were based on $3 \%$ of the capital investment. Property taxes and insurance costs were also based on $3 \%$ of the capital investment. Overhead expenses were estimated to be about $75 \%$ of the total labor and maintenance cost. The total manufacturing 
cost shown in Table 3.2 does not include costs for royalties, financing, or research and development. These additional costs could increase the manufacturing costs considerably.

\subsection{MARKET ANALYSIS}

Table 3.4 summarizes the overall economics of producing cyclohexanol via the Alkox process based on the process flow scheme and parameters selected. This analysis is on a before-tax basis, except for property taxes. This process would have a pay-back period of about four years. A discounted cash flow analysis of this project yields a $22 \%$ rate of return assuming a $20-y r$ plant life. This result was not compared with current technology due to the early stage of development of the Alkox process.

It is possible that the economic attractiveness of this process for cyclohexane oxidation could be improved if the basis for analysis were changed to include nitric acid oxidation of cyclohexanol to adipic acid. Most cyclohexanol produced is converted to adipic acid. Combining the two processes may result in a higher overall efficiency than if the two processes were treated separately. For example, the processes could be integrated to improve heat recovery.

TABLE 3.4. Overall Cyclohexane Oxidation Economics via Alkox

Total Fixed Investment Cost

Cyclohexanol Product Value Total Manufacturing Cost

Net Income

\begin{tabular}{|c|c|}
\hline \multicolumn{2}{|c|}{$\$ 110$ Million } \\
\hline \$/lb Cyclohexanol & \$Million/Year \\
\hline $\begin{array}{c}0.85 \\
(0.72)\end{array}$ & $\begin{array}{c}170 \\
(144)\end{array}$ \\
\hline
\end{tabular}

0.13 


\subsection{REFERENCES}

Chemical \& Engineering News. 1986. "Cyclohexane," 64(40) p. 14.

Chemical Marketing Reporter. July 15, 1991. 240(3).

Farrar, G. L. 1991. "How Indexes Have Changed." 0il and Gas Journal, $89(13): 66-67$.

Guthrie, K. M. 1969. "Data and Techniques for Preliminary Capital Cost Estimating." Chemical Engineering, pp. 114-142.

Hall, R. S., J. Matley, and K. J. McNaughton. 1982. "Current Costs of Process Equipment." Chemical Engineering, 89(7):80-116.

McKetta, J. J. and W. A. Cunningham. 1977. Encyclopedia of Chemical Processing and Design, Volume 2 pp. 128-146. Marcel Dekker, Inc., New York.

Perry, R. H. 1984. Perry's Chemical Engineering Handbook, Sixth Edition, pp. 13-37, 18-7. McGraw-Hil1 Book Company, New York. 

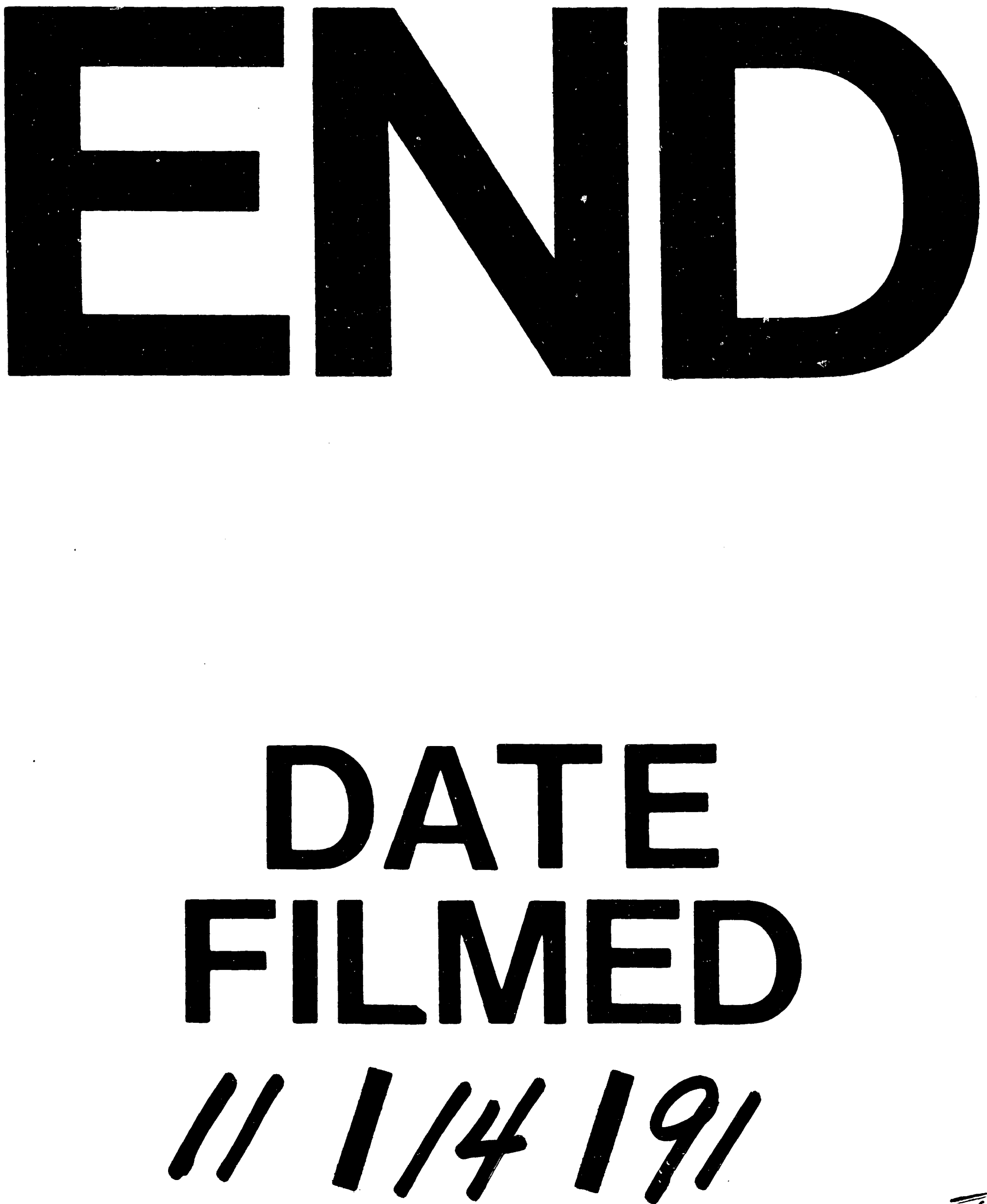
